\title{
Immunobiology of HLA Class-Ib Molecules in Transplantation
}

\author{
Vadim Jucaud*, Mepur H. Ravindranath, Paul I. Terasaki \\ Terasaki Foundation Laboratory, 11570 W. Olympic Blvd, Los Angeles, CA 90064, California, USA
}

Received: August 18, 2015; Accepted: September 23, 2015; Published: October 30, 2015

*Corresponding author: Vadim Jucaud, Terasaki Foundation Laboratory, 11570 W. Olympic Blvd, Los Angeles, CA 90064, USA, Tel: +310-4796101; Fax: +310-445-3381; E-mail: vjucaud@terasakilab.org

\section{Absract}

The objective of this review is to elucidate the role of HLA-Ib molecules in transplantation after elucidating their immunobiological potential. Structurally, the non-classical HLA-Ib molecules (HLA-E, HLA-F and HLA-G) are less polymorphic than HLA-Ia molecules. In transplantation, HLA-Ib molecules are emerging as immune regulators, functioning as ligands for immunomodulatory cell surface receptors expressed by the subsets of NK and CD8+ T cells-the major players in allograft rejection.

HLA-E is the most pleiotropic molecule in an allograft setting; it can interact with both inhibitory (CD94/NKG2A) and activating (CD94/NKG2C) receptors expressed by NK and CD8+ T cells. This interaction is dependent on the nature and source of peptides presented by HLA-E. When HLA-Ia-derived peptides are presented, HLA-E interacts with CD94/NKG2A, inhibiting the cytotoxic cell functions that promote graft survival. When the HLA-G leader sequence is presented, it interacts mainly with CD94/NKG2C to activate the cytotoxic cells, leading to graft rejection. In addition, HLA-E can present viral and bacterial peptides that can bind to both CD94/NKG2 receptors, and also can interact with the other receptors of CD8+ cells, enhancing the risk of allograft rejection.

HLA-G and HLA-F can promote graft acceptance by binding to another family of receptors: the Ig-like transcripts (ILT2/ ILT4) expressed by NK cells. Consequently, higher levels of HLA-G on the cell surface and in circulation promote graft acceptance, survival, and immunosuppression-free status for graft recipients. In contradistinction, overexpression of HLA-Ib results in higher risk of developing Graft-versus-Host Disease (GvHD) in cell transplantation.

Soluble HLA-Ib (sHLA-Ib) molecules are augmented in circulation during injury, inflammation and transplantation. The sHLA-Ib can be free or associated with $\beta 2$-microglobulin. In addition, sHLA-Ib molecules occur in a variety of conformations (isoform); as a result, HLA-Ib exposes epitopes to different immune components, contributing to antibody production. These antibodies can be monospecific or polyreactive. Binding of the monospecific antibodies can block the interaction of HLA-Ib with inhibitory receptors on cytotoxic cells, affecting graft survival. Polyreactive antibodies that bind to both cryptic and non-cryptic domains can affect routine HLAIa antibody screening and organ allocation. The antibodies binding to a cryptic domain are capable of suppressing blastogenesis and proliferation of CD4+ T cells as well as secretion of HLA antibodies by B cells; both could prolong graft survival.

Keywords: HLA-Ib; HLA-E; HLA-F; HLA-G; Transplantation outcome; HLA antibodies

\section{Abbreviations}

APC: Antigen-Presenting cells; $\beta 2 \mathrm{~m}$ : Beta2-Microglobulin; BMT: Bone Marrow Transplantation; DSA: Donor-Specific Antibody; ER: Endoplasmic Reticulum; GvHD: Graft-versus-Host Disease; HLA: Human Leukocyte Antigen; HSCT: Hematopoietic Stem Cell Transplantation; IFN: Interferon; ILT2: Ig-like Transcript 2; ILT4: Ig-like Transcript 4; MHC: Major Histocompatibility Complex; MLR: Mixed Lymphocyte Reaction; mAbs: Monoclonal

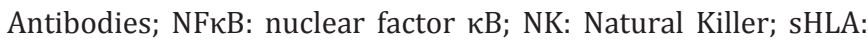
Soluble HLA; TCR: T Cell Receptors; URR: Upstream Regulatory Region; UTR: Untranslated Region.

\section{Introduction}

In humans, the Major Histocompatibility Complex (MHC) is called the "Human Leukocyte Antigen" (HLA). It consists of more than 200 genes located on chromosome 6 (6p21.31). There are three groups in this large gene family: class I, class II, and class III. The MHC class I genes are divided into classical HLA-Ia (HLA-A, -B and - $\mathrm{Cw}$ ) and non-classical HLA-Ib (HLA-E, -F and -G). The MHC class II genes include HLA-DR, -DQ and -DP. The MHC class III genes include components of the complement system involved in inflammation and other immune system activities. Every individual inherits a pair of each MHC gene, one maternal and the other paternal.

The classical HLA-Ia molecules are expressed on the surface of all nucleated cells except those of specialized tissues such as the brain [1]. HLA-II molecules are expressed on the surface of most endothelial cells and other specialized tissues and cells, such as B cells [2]; indeed, HLA-II molecules are primarily expressed by Antigen-Presenting Cells (APC) [3] and are critically involved in promoting adaptive immunity $[4,5]$. Most importantly, the endothelium, which acts as a functional barrier between the vessel wall and the blood stream, expresses both HLA-I and -II on its surface. In transplant immunology, cell surface HLA-Ia and HLA-II influence the outcome of the allograft survival $[6,7]$ due to their high polymorphism $[8,9]$. Without immunosuppression, the fate of the allograft in the host depends on the degree of genetic compatibility between the donor and recipient, and is dependent on the effect of the sum of matches or mismatches [10].

HLA genotypes of donor and recipient [11] and the antibodies 
generated against donor HLA in the recipient are critical for understanding the post-transplantation course of an allograft [12]. When a donor and a recipient do not share one or more HLA alleles of their genotype, it is referred to as a mismatch. A minimal mismatch between donor and recipient HLA genotypes favors better allograft survival since mismatched HLAs become "non-self" antigenic targets recognized by the recipient immune system, resulting in a cell- and antibody-mediated immune response, consequently damaging allograft integrity and function and leading to allograft rejection.

Antibody response against a donor-derived HLA alleleknown as Donor-Specific Antibody (DSA)-can be detrimental to allograft survival, so the evidence that, DSA is present prior to transplantation, is critical for an appropriate organ allocation since post-transplant DSA places the allograft at the risk of rejection [12]. Therefore, HLA-Ia and -II, and the antibodies generated by them in the circulation of recipients, have been the major focus in the immunobiology of clinical transplants. It is in this context that the recent discovery of non-classical HLAIb molecules brings a new dimension to the immunobiology of transplantation and a reappraisal of graft tolerance and/or acceptance.

Unlike classical HLA-Ia, non-classical HLA-Ib genes and molecules are oligomorphic, with restricted and selective tissue distribution $[13,14]$. Our understanding of the structural dynamics and functionality of HLA-Ib is progressively increasing, though HLA-Ib has yet to be fully characterized. Recent reports have attributed immunomodulatory functions to these molecules, and antigen presentation for HLA-E only; they may play an important role in immune responses and regulation, both in innate and adaptive immunity-i.e., through interactions with, respectively, Natural Killer (NK) cells, dendritic cells, and naive/ effector T and B lymphocytes, antibodies [15]. The HLA-Ib molecules are capable of interacting with cell-surface receptors present on specific immune-cell subsets, inducing activation or inhibition of signaling cascades within such specific immune cells as NK cells $[15,16]$. These functions are apart of the innate immunity [17]; e.g., HLA-Ib is expressed during pregnancy, playing a major role in tolerance of the fetus-the only true physiological analog of a semi-allograft [18]. Therefore, the innate immunity of HLA$\mathrm{Ib}$ is often attributed to those molecules' tolerance-inducing functions, by interacting with cell surface receptor located on cells that are part of the innate immune system, such as NK cells and macrophages.

As part of adaptive immunity [18], HLA-E is capable of binding to peptides for antigen presentation in order to monitor cellular stress, integrity and function [19]. HLA-G is capable of modulating the adaptive immunity [20], as well as exerting antigen-presenting functions, although the latter is not its primary function [21,22]. HLA-Ib molecules also can generate a pool of antibodies in vivo, which can be either monospecific or polyreactive (cross-reactive with other HLA-I molecules) $[23,24]$, thus pointing out the immunogenic potential of HLA-Ib molecules in vivo [25-27]. The specificity of such antibodies can impact the outcome of transplantation, as well as the allocation of organs. HLA-Ib molecules are thus capable of playing a role in the adaptive immunity linked to organ transplantation.

The low polymorphism and relative invariance of nonclassical HLA-Ib molecules seems to define their functions in the allograft microenvironment [28]. Their precise role, whether protective or pathogenic, remains to be clarified. As observed, HLA-Ia and - Ib and the antibodies elicited by them may play a role in organ transplantation. This review sheds light on this aspect of innate and adaptive immunity in understanding the immunobiology of HLA-Ib in transplantation.

\section{HLA-Ib mediated innate immunity}

HLA-Ib is naturally occurring molecules; they are primarily characterized during pregnancy and are considered to play a role in the tolerance of the fetus-the physiological equivalent of a semiallograft $[29,30]$. The engineering of HLA-Ib tetrameric complexes was used to study their function and potential ligands [31]. Their interaction with different immunomodulatory (activating and/ or inhibiting) cell-surface receptors present on NK cells and macrophages signify their role in the innate immunity; these receptors include CD94/NKG2, Ig-Like Transcript 2 (ILT2), Iglike transcript 4 (ILT4), KIR2DL4, and CD160.

\section{HLA-E}

HLA-E has 17 alleles (1 null allele), encoding 6 proteins [9], and is expressed in most tissues at low levels. Like HLA-Ia, HLA-E occurs on the surface of cells as a trimolecular complex comprised of HLA-E heavy chain, $\beta 2$-microglobulin $(\beta 2 \mathrm{~m})$ and a peptide. In addition, HLA-E can be released into the microenvironment of the allograft and in circulation as soluble HLA (sHLA)-E $[32,33]$. In contrast to HLA-Ia, HLA-E binds to a restricted set of peptides, commonly derived from the leader sequence of HLA-Ia and HLA-G molecules [34-36]; it can also bind to viral, bacterial and stress protein-derived peptides $[15,19,37]$. Two variants of HLA-E are well studied: the difference between them lies in one amino acid at position 107, located on a loop between $\beta$-strands in the $\alpha 2$ domain of the heavy chain, one with arginine at position 107- HLA-E*01:01 (HLA-E ${ }^{\mathrm{R} 107}$ )-and the other with glycine at the same position, HLA-E*01:03 (HLA-E ${ }^{\mathrm{G} 107}$ ) [38]. The difference in the amino acid residue is significant in terms of charge, size and conformation [28], affecting the relative peptide binding affinity of each allele, and consequently the cell-surface expression of HLA-E.

Several factors can upregulate HLA-E expression on normal and malignant cells. Proinflammatory cytokines-e.g., interferon (IFN)- $\gamma[28,39]-$ and the availability of several peptides [19] upregulate HLA-E expression. HLA-E acts as both an inhibitory and activating ligand for CD94/ NKG2 receptors on NK cells and T lymphocytes [31]. The interaction between HLA-E and CD94/ NKG2 receptors is influenced by the sequence of peptide presented by HLA-E $[37,40,41]$. When HLA-E is loaded with a peptide derived from the HLA-Ia leader sequence, it interacts with the inhibitory CD94/NKG2A receptor [42,43] whereas, when loaded with HLA-G leader sequence peptide, HLA-E interacts mainly with the activating receptor CD94/NKG2C [36]. HLA-E loaded with viral peptides interacts with CD94/NKG2A 
in vivo, showing a higher affinity, while, in vitro, increasing the population of NK cells that express CD94/NKG2C [41]. These observations illuminate the immunomodulatory potential of HLA-E. Furthermore, the HLA-E/ peptide complex plays a crucial role in immunosurveillance mediated by NK cells and T lymphocytes, and is thus involved in both innate and adaptive immunity [37].

\section{HLA-G}

HLA-G has 50 alleles ( 2 null alleles), encoding 16 proteins [9] with 7 protein isoforms [44]. Four of these proteins are membrane-bound (HLA-G1, -G2, -G3 and -G4), while 3 are soluble (HLA-G5, -G6 and -G7) [45]. HLA-G1 is the full-length heavy chain, having $\alpha 1, \alpha 2$ and $\alpha 3$ helices, a transmembrane domain, and a cytoplasmic tail associated with $\beta 2 \mathrm{~m}$. HLA-G2 lacks the $\alpha 2$ domain, HLA-G3 has only the $\alpha 1$ domain, and HLA-G4 lacks the $\alpha 3$ domain [44]. The three sHLA isoforms, HLA-G5, -G6 and -G7, are the counterparts, respectively, of HLA-G1, G-2 and -G3. HLA-G5 and -G6 retain intron 4, and HLA-G7 retains intron 2 , both including a stop codon that prevents the translation of the transmembrane domain and cytoplasmic tail [44]. The high diversity of HLA-G molecular structures is due to the alternative splicing of the primary transcript [46], suggesting the versatility of HLA-G molecules in vivo.

HLA-G immunoregulatory properties are attributed mainly to the inhibition of different immune-cell populations. The interaction of HLA-G with immune effector cells is mediated by ILT2 on T cells, B cells, NK cells and APC, by ILT4 on APC (myeloid cells), by KIR2DL4 on T cells and NK cells, and by CD160 on T cells, NK cells and endothelial cells [45]. However, earlier studies using engineered HLA-G tetrameric complexes showed positive binding of HLA-G on CD14+ monocytes, especially a CD16+ subset; in contrast, this HLA-G tetramer did not significantly bind to CD56+ (NK cells), CD3+ (T cells) or CD19+ (B cells) [31]. HLA-G tetramers may fail to bind to certain ligands if the affinity is insufficient or if cell-surface expression is low, which explains the negative staining of immune cells having HLA-G ligand on their surface, and also implies that the factors augmenting both the ligand and receptors are prerequisites for initiating immunomodulation.

\section{HLA-F}

HLA-F is the least investigated and understood of nonclassical HLA molecules, but it has a structure similar to that of HLA-Ia and -Ib, and has 22 alleles, encoding 4 proteins [9]. Unlike HLA-Ia, it has an intracytoplasmic domain [47]. Although HLA-F associates with $\beta 2 \mathrm{~m}$ [48], no information is available on peptide presentation. It is thought to be biologically similar to other HLAIb molecules, such as in pregnancy $[29,30]$ and cancer $[32,49]$; HLA-F also occurs in circulation as SHLA-F [32] like other sHLA-I molecules. However, the exact function of HLA-F remains to be elucidated. As with other HLA-I molecules, HLA-F expression is upregulated by IFN- $\gamma$. The IFN-stimulated response element motif of HLA-F displays higher homology to HLA-Ia loci than to HLA-Ib loci [50]. In addition, HLA-F expression is inducible by nuclear factor $\kappa B(N F \kappa B)$ through the $\kappa B 1$ site of enhancer $A$, located in the proximal promoter region [51].
No cell-surface expression of HLA-F is observed on any of the resting T-cell, B-cell, or NK-cell subsets despite the presence of intracellular HLA-F [52]; however, it is upregulated on activated lymphocytes [52] although there is no difference in the total level of HLA-F proteins before or after activation. The intracellular expression of HLA-F is independent of lymphocyte activation, but surface expression is promoted upon activation. What are the most important, regulatory $\mathrm{T}$ cells do not express HLA-F upon activation, in contrast to memory T cells. Moreover, HLA-F was found to be entirely dependent on its cytoplasmic tail for export from the Endoplasmic Reticulum (ER) [53]- in contrast to HLAIa molecules-suggesting an alternative function for HLA-F that is independent of loading with peptides in the ER.

The HLA-F molecule is known to bind to the surface of monocytes, including cells in both CD14+high and CD14+mid populations [54] and to a subpopulation of CD19+ B cells, but not to CD56+ NK cells or CD3+ T cells. HLA-F was shown to bind to ILT2 and ILT4 receptors [31,54]; however, the interaction with ILT2 and ILT4 was only partially inhibited by monoclonal antibodies (mAbs) specific for ILT2 and ILT4. So HLA-F may also interact with other receptors expressed on $B$ cells and monocytes [31]. Interestingly enough, HLA-F may dimerize or combine with $\beta 2 \mathrm{~m}$-free HLA-Ia to present exogenous peptide and/or to interact with NK cells [55-57]. This is indeed a significant finding, and deserves attention, because of its significance in organ transplantation.

In conclusion, HLA-Ib molecules are essential for the normal development of human fetuses, and are able to induce the acceptance of the fetus by the mother even though they probably share only one HLA haplotype. It certainly would seem that the cell-surface expression of HLA-Ib molecules on the allograft-as well as soluble HLA-Ib in circulation-may play a role in allograft survival, particularly considering the major actors in allograft rejection (NK cells, CD4+ and CD8+ T cells) [58]. Figure 1 summarizes how HLA-Ib molecules expressed on the surface of an allograft can affect transplantation outcome. Only the innate immunity mediated by HLA-Ib molecules has been described in a transplant setting. HLA-E expressed on the allograft interacts with CD94/NKG2A inhibitory receptors or CD94/NKG2C activating receptors, and this interaction depends on the peptide loaded onto HLA-E [36]. When HLA-E is loaded with a peptide derived from the leader sequence of HLA-Ia molecules, the HLA-E/HLAIa-peptide complex interacts with CD94/NKG2A expressed on NK and T cells $[36,37]$, which leads to the inhibition of cytotoxicity [40] and cell-mediated damage of the allograft tissue and, in turn, leads towards graft acceptance. In contrast, HLA-E loaded with a peptide derived from the leader sequence of HLA-G molecules will preferentially bind to CD94/NKG2C activating receptors [41], leading to the activation of cytotoxicity and secretion of cytokines, in turn promoting antibody production and eventually graft loss. This is important from the perspective of viremia (CMV, BK virus) associated with the allograft as part of adaptive immunity. HLA-G expressed on the allograft interacts with ILT2, ILT4 and KIR2DL4 receptors on NK and T cells, leading to the inhibition of cytotoxicity and possibly towards graft acceptance $[29,45]$. Similarly, HLA-F will interact with ILT2 and ILT4 


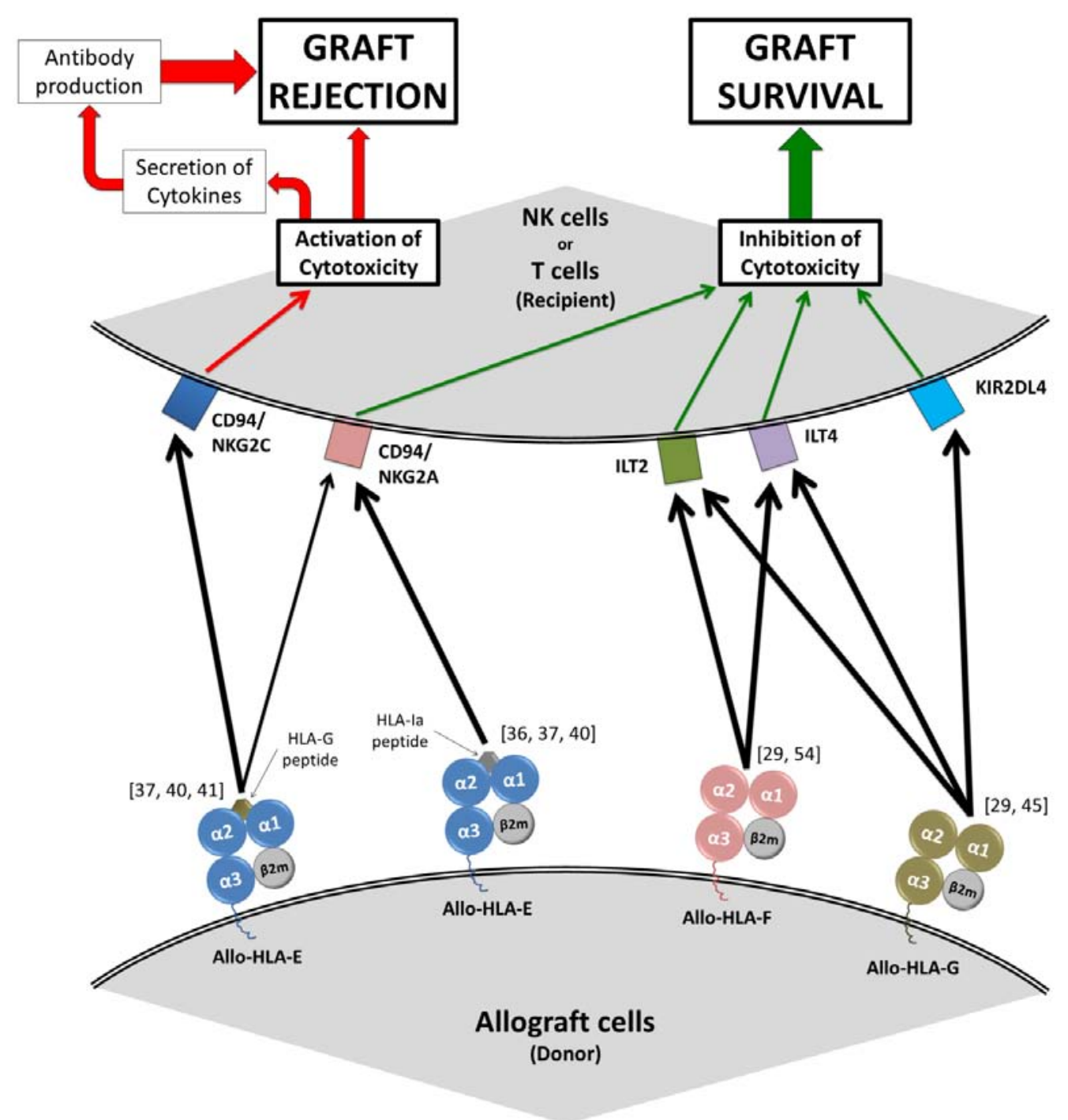

Figure 1: The innate interaction between HLA-Ib molecules and their respective immune receptors can affect transplantation outcomes. HLA-E molecules expressed on the surface of the allograft, can present peptides derived from the leader sequence of HLA-Ia and HLA-G. When HLA-E is presenting a non-allogeneic peptide, allograft cells inhibit the cytotoxic activity of NK and T cells by interacting with CD94/NKG2A receptors, inducing graft acceptance. However, HLA-E loaded with a peptide derived from HLA-G leader sequence interacts mainly with CD94/NKG2C receptors, leading to the activation of cytotoxicity, and thus rejection. HLA-G molecules expressed on the surface of the allograft can interact with ILT2, ILT4, and KIR2DL4 receptors expressed on the surface of NK and T cells, thus inhibiting the cytotoxic activity of NK and T cells, which can induce graft acceptance. Similarly, HLA-F molecules expressed on the surface of the allograft can interact with ILT2 and ILT4 receptors expressed on the surface of NK and T cells, possibly inducing graft acceptance; however, cell surface expression of HLA-F was not demonstrated on allograft.

Abbreviations: ILT2: Ig-like transcript 2; ILT4: Ig-like transcript 4; KIR2DL4: Killer cell immunoglobulin-like receptor 2DL4; $\beta 2 \mathrm{~m}$ : beta 2-microglobulin.

receptors $[29,54]$ leading to the inhibition of cytotoxicity and graft acceptance; however, it remains to be elucidated whether allograft-associated vascular and endothelial cells, infiltrating leukocytes, can express HLA-F on their surface. In the case of Bone Marrow Transplantation (BMT) or Hematopoietic Stem Cell Transplantation (HSCT), HLA-F can be expressed on donor immune cells only if they become activated [52]. A remaining question arises with these observations: what is the influence of a specific HLA-Ib genotype on the outcome of transplantation? Should HLA-Ib typing be considered in evaluating the degree of risk in organ transplantation?

\section{Non-Classical HLA-Ib and Transplantation Outcome}

In spite of the low polymorphism of HLA-Ib molecules, their allelic variants produce protein variants with divergent cellular expression, peptide presentation and soluble forms. While HLAIa and HLA-II typing of both recipients and donors is routinely performed prior to organ transplant, the importance of typing HLA-Ib has not yet become widely acknowledged. It is interesting that HLA-E mismatches were observed in patients with matched HLA-Ia [59-61]. Paradoxically, the immunomodulatory 
mechanisms mediated by HLA-Ib can be expected to play a role in promoting graft acceptance [47,62], particularly in patients without viremia. This aspect of immunomodulation by HLA-Ib may clarify the variability observed in the duration of graft survival in transplants with HLA-Ia and -II matches and in mismatched ones when the time between DSA appearance and graft rejection was substantial [12]. It remains to be seen whether the presence of HLA-Ib specific alleles can predict transplantation outcome.

\section{HLA-Ib: Role in histocompatibility}

Histocompatibility of HLA-Ib molecules is attributed to their cell-surface expression and their release into circulation as sHLA $[38,62]$. Although, HLA-Ib molecules are oligomorphic, they can induce in transplant patients a cellular and/or humoral immunological response directed against their polymorphic residues; and, like minor histocompatibility antigens, they can affect allograft survival $[12,47]$. Specific genotypes of HLA-E or HLA-G are associated, respectively, with the protein expression on the cell surface and the release of the soluble form in circulation. Indeed, the coding and non-coding allelic regions-respectively, exons and introns (plus 5' and 3' untranslated regions)-and the nature of the peptide presented affect the stability of the messenger (m) RNA and the mature protein. This leads to variable levels of protein expression [19,43,45,62-64]. On the other hand, HLA-F is expressed on the cell surface of lymphocytes only upon activation [52] and can be released into the circulation in a soluble form [32]; however, there is not yet any evidence of the effect of specific genotypes of HLA-F or the level of cell-surface expression. The role of HLA-F in histocompatibility remains to be evaluated.

The level of cell-surface expression of HLA-E in PBMC was significantly higher in subjects with homozygous HLA-E*01:03 than in those with homozygous HLA-E*01:01. The same was true for peptide-induced HLA-E surface expression. In addition, the level of cell-surface expression was dependent on the sequence of the peptide presented by HLA-E [19]. Indeed, the CMV, HLA-B7 and HLA-B15 peptides induced higher expression of cell-surface HLA-E than those derived from Hsp60, and the induction of surface HLA-E is always significantly higher in patients with homozygous HLA-E*01:03 regardless of the peptide presented. The expression of cell-surface HLA-E is regulated at the posttranscriptional level since there is no difference in mRNA expression levels between HLA-E genotypes or between peptideinduced cell-surface HLA-E [19]. These observations indicate that the cell-surface expression of HLA-E is dependent on HLA-E genotypes and the nature of peptides presented by the HLA-E molecule. There are functional implications for the allelic differences in the surface expression of HLA-E. Higher cell surface expression of HLA-E*01:03 may result in a greater capability of inhibiting immune cells through CD94/NKG2A receptors [65] provided that the peptide presented by HLA-E is derived from the leader sequence of HLA-Ia. Therefore, HLA-E*01:03 homozygous recipients may be better graft "acceptors" than HLA-E*01:01 patients provided that the allograft is devoid of viremia. Withal, a HLA-E genotype match should be beneficial in transplantation because the HLA-E homozygous state has been shown to be associated with transplantation outcomes, especially in BMT and HSCT $[59,66,67]$.

The expression of HLA-G on the cell surface and its soluble form is associated with its polymorphism, both in the coding and non-coding regions of the allele [35]. The polymorphism in the coding region of HLA-G genes creates protein variants, including aberrant or truncated proteins [68]. HLA-G*01:01:03 and HLA-G*01:05N alleles have been shown to produce low levels of sHLA-G compared with HLA-G*01:01:01; in contrast, the HLA-G*01:01:04 allele produced high levels of sHLA-G $[46,69]$. These alleles are likely linked to their cell-surface expression level, although more studies are needed to elucidate this possibility. The non-coding regions of HLA-G alleles are called "the 5' Upstream Regulatory Region (URR)" and the " 3 ' Untranslated Region (UTR)." The 5'URR polymorphism (C $\rightarrow \mathrm{G}$ ) at position $-725 \mathrm{bp}$ in patients showed no detectable sHLA-G whereas that of patients with no substitution $(C \rightarrow G)$ at the same position did, which underscores the functional implications of the position in vivo [70]. The HLA-G polymorphism observed in the 3'UTR is called "the 14bp insertion" (or deletion). The 3'UTR $14 \mathrm{bp}$ insertion homozygous state is associated with lower levels of sHLA-G, the opposite being true for the 3'UTR 14bp deletion homozygous state $[44,70,71]$. The HLA-G 3'UTR 14 bp insertion leads to a more stable mRNA affecting its rate of translation, and thus its protein expression $[44,72]$. The non-coding region of HLA-G alleles-5' URR and 3' UTR affects the cell-surface expression of HLA-G and the presence of sHLA-G in circulation.

In conclusion, the role of HLA-Ib genes and molecules in histocompatibility has attracted interest in recent years because of the implication of HLA-Ib in graft acceptance, especially in regards to inducing tolerance. Most often, it is agreed that higher levels of HLA-Ib expression is associated with better allograft survival outcome $[47,62]$, but some exceptions exist, such as in BMT, where higher levels of HLA-G expression is associated with higher risk of acute graft-versus-host disease (GvHD) [71]. Since heart, liver, kidney and lung allografts express HLA-Ib on their cell surface $[47,62,73]$, even if the expression of HLA-Ib is low compared with that of HLA-Ia, both cell-surface expression and release in circulation of HLA-Ib are capable of affecting transplantation outcome. Selected patients with a high level of HLA-Ib expression, based on HLA-Ib genotypes, could benefit from lower immunosuppressive protocols while others could benefit from alternate therapeutic strategies.

\section{HLA-E, viremia and transplantation}

As part of adaptive immunity [15], HLA-E can present viral and bacterial-derived peptide from CMV, HCV, HIV, EBV, influenza, salmonella enterica and mycobacterium; and the HLA-E/ peptide complex can interact with T-Cell Receptors (TCR) [40]. In transplantation, the potent immunosuppressive treatment regimen employed currently improves graft survival, but at the cost of increasing the recipient's susceptibility to infections [74] as well as to pre-existing viremia. Indeed, the viremia status of both donor and recipient plays a role in allograft failure. Poor survival of allografts in recipients with CMV or BK viremia is well known [75,76], although the mechanism underlying the association between viremia and allograft rejection has 
not been clarified. However, it has been shown that allograftinfiltrating CD8+ T cells can recognize and kill allogeneic (CMVinfected) endothelial cells by the interaction of their TCR with HLA-E that has been loaded with a viral peptide [77]. The direct interaction between that HLA-E loaded with a viral peptide and activating receptors (CD94/NKG2C) on cytotoxic NK and CD8+ $\mathrm{T}$ cells, serves to activate antiviral activity capable of controlling infection and also has the potential of destroying the allografts that harbor viruses in the recipients. Figure 2 illustrates this process, which contributes to allograft rejection. Terasaki and his co-investigators [78] developed a strategy to control the cytotoxic activity of activated CD8+ T cells to prevent allograft rejection. They reported that heart transplant recipients treated with pravastatin showed a decrease in the incidence of clinically severe acute rejection episodes, in the incidence and progression of transplant coronary vasculopathy, and in rejection mediated by NK cell cytotoxicity. It is possible that allograft recipients with CMV or BK viremia may be much benefited by statin treatment, which indirectly counteracts HLA-E-mediated augmentation of NK and CD8+ T cell cytotoxicity.

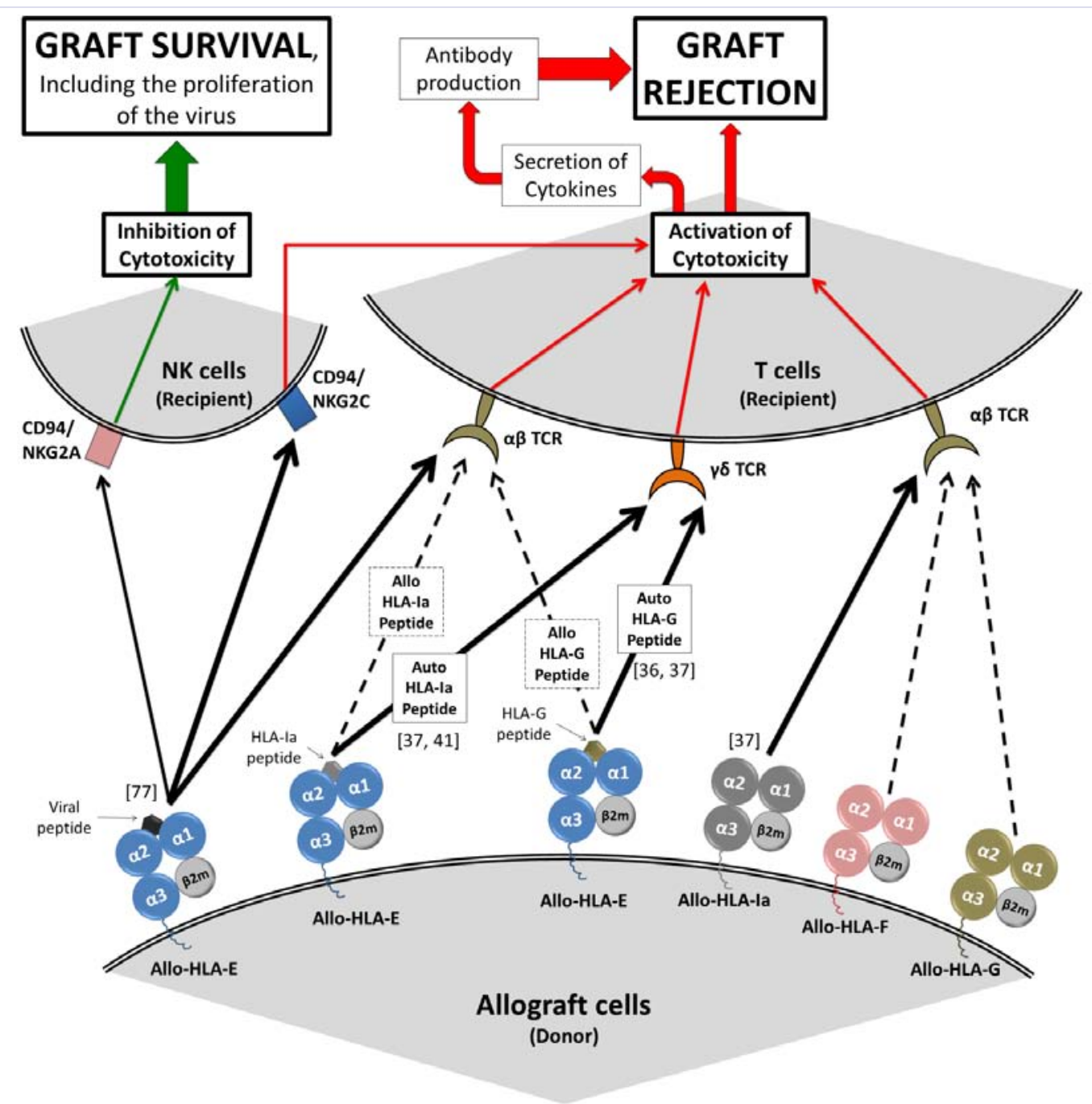

Figure 2: The adaptive interaction between HLA-Ib molecules and their respective immune receptors can affect transplantation outcomes. Allogeneic HLA-Ia molecules, expressed on the surface of the allograft, are recognized by T cells as "non-self," which will eventually lead to graft rejection. The same principle can be applied to HLA-G and HLA-F if they are recognized by T cells as "non-self"-although there is no evidence of this interaction. HLA-E molecules expressed on the surface of the allograft, can present peptides derived from the leader sequence of HLA-Ia and HLA-G. Only when HLA-E is loaded with auto-peptide (from HLA-Ia and/or HLA-G), donors T cells use their $\gamma \delta$ TCR to recognize HLA-E on the allograft, leading to the production of proinflammatory cytokines, and thus to rejection. When HLA-E is presenting allogeneic peptides (from HLA-Ia and/or HLA-G), donors T cells use their $\alpha \beta T C R$ to recognize HLA-E on the allograft, thus inducing the cytotoxic activity of CD8+ T cells, promoting graft rejection. Finally, HLAE presents viral peptides when the allograft is infected. Viral peptides, presented by HLA-E, interact with $\alpha \beta$ TCR on donor's T cells or CD94/NKG2C on NK cells, leading to the activation of cytotoxicity and eventually graft loss. Depending on the nature of the viral peptides presented by HLA-E, the complex HLA-E/viral-peptide can interact with CD94/NKG2A on NK cells leading to the inhibition of cytotoxicity and thus graft acceptance; however, this mechanism leads to the proliferation of the viruses, which is detrimental to recipient survival. Dashed lines indicate possible interactions. Abbreviations: TCR: T cell receptors; $\beta 2 \mathrm{~m}$ : beta 2-microglobulin. 


\section{HLA-Ib, endothelium and transplantation}

The vascular endothelium of allografts is the main target for cellular- and/or antibody- mediated vasculopathy and rejection. HLA-E expressed on endothelial cells is overexpressed and then released into circulation upon activation of the cells by IFN- $\gamma$ [33], thus highlighting the relevance of HLA-E in transplantation. On one hand, a recipient who is HLA-E*01:03- homozygous and receives an HLA-E-matched transplant can be expected to accept the graft better because higher cell-surface expression of HLA-E*01:03 than of HLA-E*01:01 may result in a higher capability to inhibit NK cells and CD8+ T cells through CD94/ NKG2A receptors [65]. On the other hand, some T cells use their TCR to recognize HLA-E [31,41]. In vitro, HLA-E-restricted CD8+ $\mathrm{T}$ cells recognized and killed allogeneic endothelial cells [77], which can mediate graft rejection. If the HLA-E, expressed on the allograft is loaded with a peptide derived from an allogeneic HLAIa leader sequence, HLA-E-restricted CD8+ T cells may use their TCR to recognize and kill allograft cells. Although this mechanism is well demonstrated with viral peptides, it remains to be elucidated with other well known HLA-Ia peptides presented by HLA-E. Therefore, HLA-E-restricted CD8+ T cells are pathogenic during organ transplantation, that pathogenicity is mediated by the TCR recognition of the complex HLA-E/allo-HLA-Ia-peptide [37] as shown in Figure 2.

In a Mixed Lymphocyte Reaction (MLR), loading the leader sequence of HLA-G1 onto HLA-E of a donor's PBMC produced different patterns of NK-CTLs-mediated cytotoxicity [37]. NKCTLs recognize and kill donor's cells with far greater efficacy. The HLA-E/HLA-G1 leader-sequence peptide complex prevents the cytotoxicity of NK-CTLs by binding to the inhibitory receptor CD94/NKG2A. However, NK-CTLs cytotoxicity is promoted when the HLA-E/HLA-G1 leader sequence-peptide complex is recognized as "non-self" as a result of the interaction with CD94/ NKG2C or TCR. The MLR shows high levels of cytotoxicity with only one donor, possibly because the recipient's NK-CTLs and those of the donor do not share their HLA-G alleles; but more studies are needed to elucidate this point. HLA-E loaded with a peptide derived from the leader sequence of allogeneic HLA-G molecules (expressed in the allograft cells) can be recognized by CD8+ T cells by means of their TCR, inducing the activation of cytotoxicity, the secretion of cytokines, and eventually the production of antibodies, which leads to graft rejection-all, as shown in Figure 2.

HLA-G was shown to be expressed by endothelial cells and its expression and secretion upregulated in a dose-dependent manner by progesterone [79]. The induction of HLA-G expression in endothelial cells of the allograft can clearly benefit the patient by inhibiting effector cells responsible for rejection and vasculopathy. In addition, it was shown that hypoxia can modulate HLA-G expression depending on cell type and culture conditions. During pregnancy, hypoxia can upregulate HLA-G [80], but in melanoma the opposite happens [81]. In transplantation, hypoxia is a common feature during organ procurement and re-implantation [73]; this impels the conclusion that the expression of HLA-G induced by hypoxia should be investigated in a transplant setting. Even before that happens, though, the induction of HLA-G expression should not be used in patients mismatched for HLA-G because the allograft will express "nonself" antigens that could induce allograft rejection during solid organ transplantation or GvHD in BMT or HSCT.

Under certain conditions, HLA-F can be expressed on the surface of endothelial cells. Indeed, human brain microvascular endothelial cells infected by the Japanese encephalitis virus activate NFKB leading to functional HLA-F gene induction and cell-surface expression [82]. HLA-F expression may be linked to viral infection. It remains to be elucidated whether allografts with viremia express HLA-F. If so, HLA-F could participate in allograft acceptance by binding to ILT2 and ILT4 inhibitory receptors on NK cells to induce immune evasion [56] of allograft cells.

\section{HLA-Ib in graft-versus-host disease}

Most studies of the expression of HLA-Ib molecules and the outcome of transplantation have agreed that higher levels of HLAIb expressed on the surface of cells-or of sHLA-Ib in circulationare associated with an overall longer allograft survival. However, those patients who are at risk of developing GvHD (e.g, BMT and HSCT recipients) may not benefit from the increased expression and release of HLA-Ib molecules. These can be expressed on both allograft and donor cells, and despite of their low polymorphism, HLA-Ib alleles can be mismatched even when donor and recipient are HLA-Ia identical [59-61]. The mismatches in HLA-Ib alleles increase the number of allogeneic targets recognized by the recipient, and, in BMT and HSCT, the number of allogeneic targets recognized by the donor's cells, that lead to GvHD.

The HLA-E genotype is associated with GvHD in both BMT and HSCT. An HLA-E*01:01-homozygous state was a risk factor for early bacterial infections and transplant-related mortality in unrelated-donor BMT [59]. Allele frequencies within the studied cohort were similar to those previously reported in various population groups (donor group HLA-E*01:01 was 60\% and HLA-E*01:03 40\%; recipient group HLA-E*01:01 was 56.5\% and HLA-E*01:03 43.5\%). Among the 77 pairs in that study, 39\% had different HLA-E alleles despite being identical for HLA-C and -A alleles. This further confirms the existence of weak linkage disequilibrium between the classical HLA and HLA-E loci [59]. In HLA-E-matched allogeneic HSCT, the HLA-E*01:03/01:03 homozygous genotype has a protective role since it is associated with a lower frequency of acute and chronic GvHD, and it is associated with improved overall survival compared with other HLA-E genotypes [66,67]. Therefore, lower HLA-E expression on allograft-associated with the HLA-E*01:01 homozygous state [19] may lead to complications such as GvHD because the recipient may be less capable of inhibiting immune cells through CD94/ NKG2A receptors. It is clear that HLA-E should be matched in BMT or HSCT because it leads to a transplant that is less at risk of developing GvHD. More studies are needed to evaluate how much HLA-E must be expressed on allograft cells to sustain acceptance before the antigenic load of allogeneic HLA-E triggers an allogeneic immune response leading to rejection. Of course, other factors (e.g., epigenetic factors regulating HLA-I expression) [83] may influence the outcome of BMT and HSCT, with their risk of 
developing GvHD, or of transplants between monozygotic twins because the level of DNA methylation-an epigenetic feature that changes in response to the environment-is able to differentiate between monozygotic (hence HLA-identical) twins [84].

The HLA-G polymorphism observed in the 3'UTR-which, as noted is called "14bp insertion or deletion"-is associated with a high risk of acute GvHD [44]. It was shown that recipients, homozygous for HLA-G 3'UTR 14bp deletion, had a high risk of acute GvHD [71], and that patients, homozygous for HLA-G 3'UTR $14 \mathrm{bp}$ insertion, had a moderate association with a lower risk of acute GvHD compared to HLA-G 3'UTR 14bp heterozygous and HLA-G 3'UTR 14bp deletion homozygous patients [85]. They produced high levels of sHLA-G $[70,86]$; in solid organ transplantation they experienced a low rate of rejection [44], although in BMT it was the opposite [71]. Higher levels of sHLA-G in patients homozygous for HLA-G 3'UTR 14bp deletion indicate that HLA-G expression is higher than with other 3'UTR genotypes, thus increasing the number of antigenic target available, promoting GvHD.

There is no information about HLA-F alleles and their role in GvHD, but HLA-F is a marker of activated lymphocytes [52], and upon immunological activation in patients experiencing GvHD, the donor's and recipient's immune cells will express HLA-F on their surface, so an HLA-F genotype mismatch may increase the severity of GvHD. More studies are needed to confirm this hypothesis.

These observations suggest that in BMT and HSCT, HLA-E and other HLA-Ib alleles should be matched in order to reduce the number of possible antigenic targets recognized by the donor cells. If HLA-Ib polymorphism is not matched in BMT and HSCT, then donor cells have more potential recipient targets to attack, which will result in severe GvHD in those HLA-Ib mismatched patients.

To sum up about HLA-Ib molecules, they clearly play a role in histocompatibility and they impact transplantation outcomes. The presence of high levels of HLA-Ib molecules (on the cell surface or in circulation) is usually associated with better graft acceptance, longer graft survival, and immunosuppressivefree patients; however, in the case of cell transplantation (BMT and HSCT), HLA-Ib alleles mismatches may increase the risk of developing GvHD by increasing the foreign antigenic load recognized by the donor cells. Therefore, it is still debatable whether HLA-Ib alleles should be matched for all transplants, and if so, whether the immunosuppressive function of HLA-Ib molecules is mediated by the donor's molecules or those of the recipient. Some studies emphasize that the allograft (donor cells) should be expressing HLA-Ib molecules-and at high levels-in order to evade the cytotoxic activity of NK cells and CD8+ T cells that lead to graft rejection [18,87-89] because cell-to-cell contact is mandatory for the interaction of HLA-Ib molecules and their inhibitory receptors to prevent the lysis of allograft cells by NK cells and CD8+ T cells [90]. Promoting the expression of HLAIb-rather than sHLA-Ib-by the donor's cells therefore provides the best and most specific strategy for helping allograft cells evade cell-mediated damage (or rejection). Soluble HLA-Ib will most likely participate in the regulation, differentiation, and proliferation of immune effector cells, thus participating in graft acceptance, but not directly mediating it.

\section{Immunobiology of Soluble HLA-Ib in Transplantation}

The importance of sHLA-Ib molecules is characterized by their ability to interact with different lymphocyte subsets and, what is most important, with NK and CD8 ${ }^{+} \mathrm{T}$ cells. Soluble HLA-Ib can bind to both inhibiting and activating receptors-respectively, (CD94/NKG2A, ILT2, ILT4) and (CD94/NKG2C, ILT2, ILT4). The inhibition of the cytotoxic activity of $\mathrm{NK}$ and $\mathrm{CD}^{+} \mathrm{T}$ cells, mediated by SHLA-Ib, may favor allograft survival while the activation of their cytotoxic capabilities would promote allograft rejection.

Soluble HLA-Ib can be released in the circulation by three different mechanisms: exosomal shedding, alternative splicing, and proteolytic processing $[91,92]$. Each mechanism will produce different isoforms of sHLA-Ib, contributing to a pool of sHLA-Ib in the allograft microenvironment and circulation. Soluble HLA-I levels are increased in several physiological and pathological conditions such as pregnancy, acute rejection episodes following allografts, and acute GvHD following BMT [93]. Indeed, the increased level of sHLA-I may be a result of immune activation, as shown by a rapid decrease in the level of SHLA-I following immunosuppressive therapy in patients with acute rejection episodes [94].

Previous studies have shown that SHLA-G is associated with an increased graft survival and a decrease in rejection episodes in such organ transplantation as heart [95], liver [96], kidney [96-98], lung [89] and HSCT [62]. HLA-G expressed on the allograft, and sHLA-G in circulation, may also play a role in $\mathrm{T}$-cell anergy as well as inducing immunosuppressive $\mathrm{T}$ cells [18], suggesting that the donor's molecular typing of HLA-G should be considered in allograft transplantation because HLA-G is regulated by genetic and cytokines depending on the viral or non-viral microenvironment [62]. Compared with all other sHLAIb molecules, HLA-G has a high diversity of molecular structures due to alternative splicing of the primary transcript $[44,45]$. As noted earlier, the expression of HLA-G on the cell surface and its soluble form is associated with its polymorphism in both the coding and non-coding regions of the HLA-G allele. There is a need to elucidate the kind of isoforms of HLA-G that are more potent in inducing immunosuppressive $\mathrm{T}$ cells. There may be a good correlation between higher cell-surface expression of some isoforms with higher levels of sHLA-G release from the allograft, which facilitates allograft tolerance in the recipient due to those isoforms' specific affinity for inhibitory receptors (ILT2, ILT4 and KIR2DL4) [45].

HLA-G can form disulfide-linked dimeric complexes on the cell surface and in circulation because of high preferential binding to immune inhibitory receptors; SHLA-G dimers were also found to be significantly higher in renal allograft recipients who had experienced no rejection episodes than in patients with chronic rejection [99]. In this study, the investigators evaluated 
the levels of sHLA-G1 and HLA-G5 dimers and monomer isoforms. In confirmation of their finding, the increased cellsurface expression of HLA-G on monocytes of patients with no rejection episodes was found to be associated with high levels of plasma sHLA-G dimers [100]. These observations underscore the potential of HLA-G in graft acceptance; but it remains to be determined whether this potential is due to cell-surface expression of HLA-G1 or whether its soluble form, HLA-G5, induces graft acceptance in the course of its specific mechanism of action. Possibly HLA-G5 molecules may be involved in the inhibition of immune functions by their direct interaction with ILT2 and ILT4 receptors present on the main effector cells responsible for graft rejection [18,62,64]. HLA-G1, expressed on the surface of allograft cells, inhibits the cytotoxic function of $\mathrm{NK}$ and $\mathrm{CD}^{+} \mathrm{T}$ cells through cell-to-cell contact, preventing the cell-mediated allograft damage that leads to cellular rejection. In contrast, HLA-G5 molecules interact with immune effector cells in circulation, and probably have a more potent effect in allograft rejection on $\mathrm{CD}^{+} \mathrm{T}$ cells and $\mathrm{APC}$ than do $\mathrm{NK}$ and $\mathrm{CD} 8^{+} \mathrm{T}$ cells by inhibiting alloreactivity and proliferation and by up-regulation of inhibitory receptors on their surface [18,62].

The presence of sHLA during rejection episodes [101] creates a pool of soluble antigens that can lead to the production of HLA antibodies [102,103], which supports the immunogenic potential of sHLA molecules in vivo. The greatest challenge in characterizing sHLA (classical Ia, or non-classical Ib) is the degree of homology that these molecules have. Indeed, only mAbs-particularly those that are monospecific (directed against an epitope that is unique for a specific HLA allele)-should be used to identify specific sHLA isoforms or alleles present in the sera. For example, it was shown that commercially available HLA-E mAbs recognize shared peptide sequence on HLA-Ia molecules [104]; therefore, such mAbs bind to more than one HLA-Ia or -Ib allele, decreasing the reliability of such mAbs in binding to a specific HLA-I molecule, affecting the interpretation of the results. Rarely have HLA-Ia or -Ib mAbs been characterized for their unique specificity either by screening their reactivity with a panel of HLA molecules (such as single antigen HLA beads) or by using a peptide sequence unique for the allele to inhibit the mAb's specific binding [23,104-106].

\section{Humoral immune response to HLA-Ib}

The humoral theory of transplantation proposed by Terasaki [12] envisages a primary role for HLA antibodies in post-transplantation allograft rejection. The increasing sensitivity of HLA antibody screening has dramatically improved transplantation outcomes. Routinely, only HLA-Ia and -II antibodies are tested in transplant recipients, and HLA-Ib antibodies are never considered. However, various investigations $[23,24,39,104-107]$ of HLA-Ib antibodies showed that one molecule of HLA-Ib (with or without $\beta 2 \mathrm{~m}$ ) can elicit different kinds of mAbs, some recognizing strictly the HLA immunogen used in immunization. Alternatively, these antibodies (e.g., HLA-E mAb TFL-033) [23,39] can be considered monospecific since they react to only one HLA-Ib molecule. The other antibodies generated by an HLA-Ib molecule (e.g., HLA-E mAbs TFL-006 and TFL-007) $[24,106,107]$ can react to other HLA-I molecules at various levels. Such polyreactive binding (reacting with more than one HLA-Ib and/or -Ia molecule) can be a consequence of the antibodies recognizing the amino acid sequences common to the HLA molecules [23-25,104]. So the presence of HLAIb antibodies in the serum can affect the screening of HLA-Ia antibodies. Figure 3 illustrates how HLA-Ib antibodies can affect routine HLA antibody screening and organ allocation, and it shows the possible transplantation outcomes of having HLA-Ib antibodies in circulation. There remains a need to elucidate the immunogenicity and antigenicity of HLA-Ib molecules and the complex pool of antibodies that can be produced in vivo.

In addition to its other abilities, one HLA-G gene can produce several different protein isoforms that can expose cryptic epitopes usually hidden in the full-length protein associated with $\beta 2 \mathrm{~m}$ [68]. Also, HLA-Ib molecules have been shown to homodimerize and heterodimerize on the cell surface or in circulation [55-57], which can expose cryptic epitopes recognizable by the immune system.

\section{Immunogenicity of HLA-Ib molecules}

A native HLA-Ib molecule (a trimolecular complex comprised of HLA heavy chain, $\beta 2 \mathrm{~m}$ and a peptide) may become immunogenic once the heavy chain of HLA-Ib detaches from $\beta 2 \mathrm{~m}$ or after it has undergone proteolytic alteration. Both loss of $\beta 2 \mathrm{~m}$ and proteolytic alteration will expose amino acid sequences or epitopes that have previously remained cryptic on HLA. Exposure of cryptic antigens makes the molecule immunogenic, eliciting production of antibodies. The presence of polyreactive HLA-E antibodies was observed in renal and liver transplant recipients as well as in melanoma patients [26,27]. In addition, antibodies reacting against HLA-Ib molecules (HLA-E, -F and -G) and HLA-Ia (HLA-A, -B and - $\mathrm{Cw}$ ) were present in different IVIg preparations and in the IgG-purified serum fraction from non-alloimmunized males [108]. Together, these findings provide evidence of the immunogenicity of HLA-Ib in vivo.

The immunogenicity of HLA-Ib molecules is driven primarily by polymorphic amino acids residues located on the $\alpha 1$ and $\alpha 2$ helices, leading to an immunological response directed at a unique HLA-Ib molecule as shown in Figure 3. Meanwhile, non-native forms of HLA-Ib molecules (produced by proteolytic degradation, alternatively spliced transcript, or shedding) can expose epitopes that are shared by HLA-Ib and/or HLA-Ia molecules. Such shared or common epitopes may trigger an immunological response when the immunogen is encountered, and may also trigger one when these epitopes are present and exposed on HLA-Ia or -Ib molecules other than the immunogen. Such shared epitopes may be exposed on the molecular surface (e.g., those recognized by W6/32) or may be cryptic, like those recognized by HC10, MEM02, MEM-06, MEM-07, 3D12 or by TFL mAbs TFL-006 and TFL007 [24,39,104-106,108]. The fact that HLA-Ib molecules carry epitopes shared by HLA-Ia molecules points up the possibility that shared epitopes cannot be immunogenic because if they were they should be recognized as "self"; however, the presence of natural HLA antibodies [109], HLA-E antibodies [25] in nonalloimunized males, and HLA-Ia/-Ib antibodies in IVIg [108] shows that HLA-I self-shared epitopes can become immunogenic in vivo. 
HLA-Ia or -Ib cryptic epitopes, usually hidden in a noninflammatory state, can elicit an immune response by exposing hidden amino acid residues upon inflammation; indeed, the dissociation of $\beta 2 \mathrm{~m}$ from the HLA heavy chain creates potential, newly exposed epitopes for antibody production, possibly to clear sHLA heavy chain from circulation, thus preventing possible immunomodulatory function of SHLA-Ia or -Ib.

\section{Antigenicity of HLA-Ib molecules}

Antibodies generated after the immunization of HLA-Ib molecules can produce a variety of antibodies with a variable panel of reactivity towards HLA-Ia and -Ib molecules. Indeed, the production of HLA-E mAbs, generated after the immunization of HLA-E heavy chain, produced eight types of HLA-E mAbs. These were classified based on their reactivity to a panel of HLA-Ia and -Ib molecules [24]. Monospecific antibodies-called "type 1 mAbs" in that report-bound only to the HLA-Ib molecule used as the immunogen. Low polyreactive antibodies (called "types 2, 3 and 4 mAbs") bound to more than one HLA-Ib molecule but not to HLA-Ia. Moderate polyreactive antibodies ("types 5, 6 and 7 mAbs") bound to one or more HLA-Ib molecules and to most HLA-Ia molecules. Finally, high polyreactive antibodies ("type 8 mAbs") bound to all HLA-Ia and -Ib molecules [24].

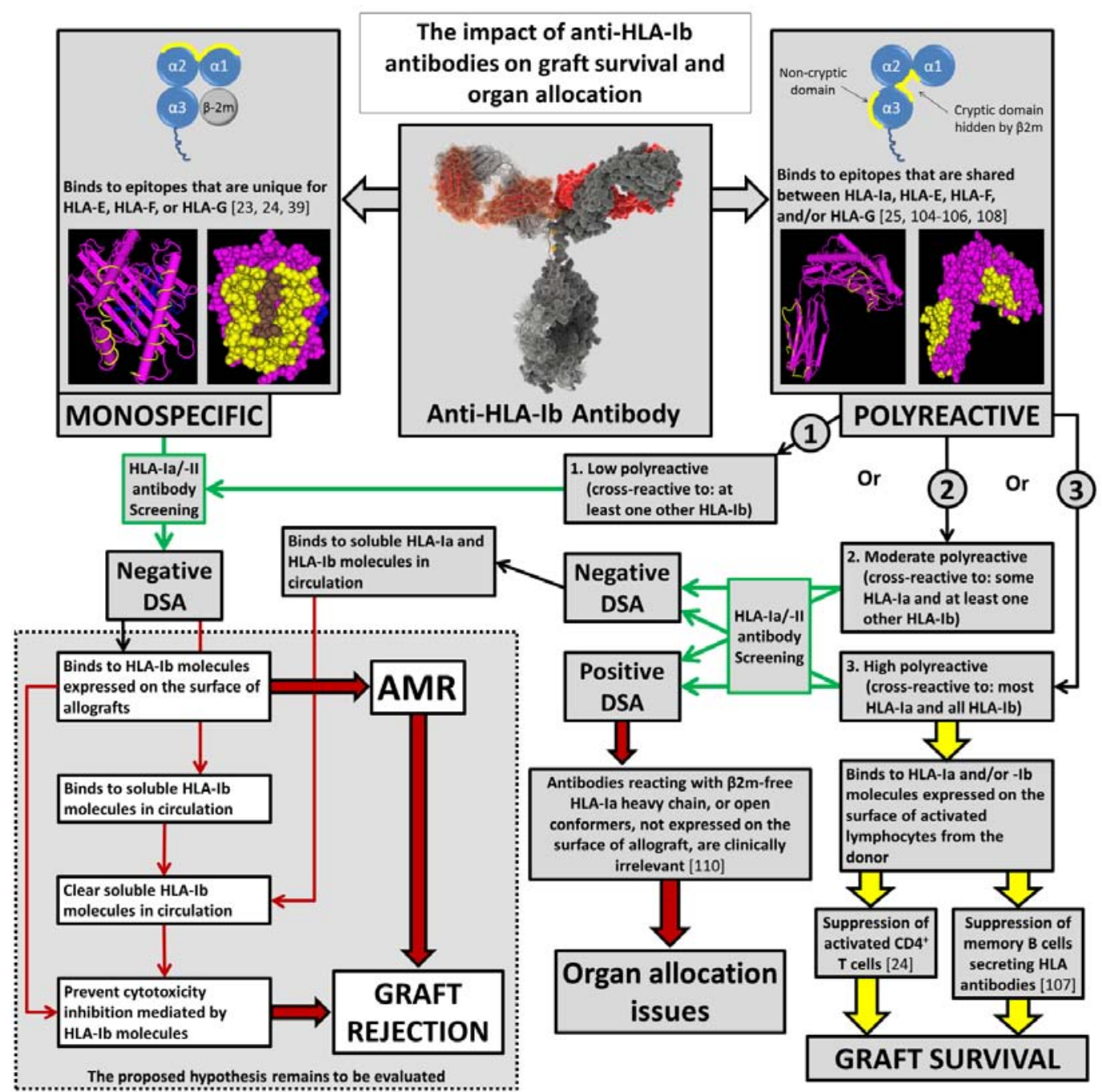

Figure 3: The pool of HLA-Ib antibodies that can be produced in transplant patients based on routine HLA-Ia and -II antibody screening, and their effect on graft survival and organ allocation. Monospecific HLA-Ib antibodies will not be detected by routine HLA-Ia and -II antibody screening, but they can bind to HLA-Ib molecules expressed on the surface of the allograft (possibly leading to AMR)-or to soluble HLA-Ib in circulation-to prevent the inhibition of cytotoxicity mediated by HLA-Ib molecules, thus leading to graft loss. Polyreactive HLA-Ib antibodies are of three kinds: (1) low polyreactive HLA-Ib antibodies that may contribute to graft lost in the same way as monospecific antibodies; (2) moderate polyreactive HLA-Ib antibodies that can affect routine HLA-Ia and -II antibody screening and thus organ allocation, and contribute to graft lost in the same way as monospecific antibodies; and (3) high polyreactive HLA-Ib antibodies that can affect routine HLA-Ia and -II antibody screening and thus organ allocation. But high polyreactive antibodies can bind to open conformers expressed on the surface of activated lymphocytes, promoting graft acceptance by suppressing activated CD4+ T cells and suppressing memory B cells' HLA antibodies secretion.

Abbreviations: AMR: Antibody-Mediated Rejection; DSA: Donor-Specific Antibodies; $\beta 2 \mathrm{~m}$ : beta 2-microglobulin. 
As shown in Figure 3, HLA-Ib molecules can produce a complex pool of antibodies that can affect routine HLA antibody screening, organ allocation, and transplantation outcomes. Monospecific (type 1) and low polyreactive (types 2, 3, and 4) HLA-Ib antibodies will not affect HLA antibody screening because HLA-Ib molecules are not represented in the routine HLA-I and -II antibody screening panel. Therefore, the presence of those types 1-4 in the serum will not affect the organ. Nonetheless, such monospecific and low polyreactive antibodies could have a negative impact on organ transplantation outcome. Both can prevent the inhibition of cytotoxicity mediated by HLA-Ib molecules by binding to sHLA-Ib molecules and clearing them from circulation. Only monospecific antibodies can bind to HLAIb expressed on the surface of the allograft, possibly leading to antibody-mediated rejection and eventual graft loss. In addition, monospecific HLA-E mAbs are capable of upregulating CD8 ${ }^{+}$ T lymphocytes [23] in vitro, which would be detrimental to an allograft recipient if such HLA-E antibodies are in the patient's serum.

On the other hand, moderate and high polyreactive HLA-Ib antibodies will affect routine HLA antibody screening because they can bind to a shared epitope exposed in the recombinant HLA protein coated on a solid matrix. Such antibodies can react with many HLA-Ia and -Ib molecules, increasing the likelihood that a patient with a polyreactive HLA-Ib antibody will be positive for DSA. That means the allocation of organ and immunosuppressive treatment is greatly affected by the pre-transplantation presence of those moderate and high polyreactive HLA-Ib antibodies because the antibodies react with DSA in vitro.

In addition, HLA-Ia screening of polyreactive HLA-Ib antibodies will show high levels of non-DSA because antibodies produced after an immunization event involving immature HLA-E [59]-or an alternatively spliced transcript of HLA-G [71] or an HLA-F/HLA-Ia heterodimer [26,43]- react with non-native HLA molecules, which are known to be present in routine HLA-Ia antibody screening [110]. Although HLA antibodies reacting with $\beta 2 \mathrm{~m}$-free HLA heavy chain or open conformers are thought to be clinically irrelevant to the outcome of transplantation [110], it has been shown that such $\beta 2 \mathrm{~m}$-free HLA heavy chains are expressed on the surface of activated cells [111], and they can homodimerize and heterodimerize [55-57] thus exposing cryptic epitopes available for the recognition of $\beta 2 \mathrm{~m}$-free, HLA heavychain antibodies $[24,57,107,108]$ detected by single antigen beads assay [24]. This suggests that HLA-Ib antibodies reacting against $\beta 2 \mathrm{~m}$-free HLA heavy chain may have a clinical relevance because polyreactive antibodies may react with donor/recipient HLA, and, although reacting with non-native molecules, they may impact transplantation outcome (Figure 3). The aforementioned moderate polyreactive HLA-Ib antibodies-cross-reactive to most but not all HLA-Ia/-Ib alleles-may exert a negative impact on transplantation by binding to SHLA-Ib, thus preventing the tolerance-inducing function of sHLA-Ib associated with graft acceptance. High polyreactive (type 8) HLA-Ib antibodies can be protective. Indeed, those antibodies, raised against HLA-E molecules and produced in vivo, can bind to open conformers expressed on the surface of activated lymphocytes, and were able to suppress both activated $\mathrm{CD}^{+} \mathrm{T}$ cells [24] and memory B-cell HLA antibody secretion [107] in vitro. Clearly, then, high polyreactive HLA antibodies, raised against HLA-Ib molecules, play a role in graft acceptance by suppressing alloreactive $\mathrm{T}$ and $B$ cells. In addition, it was shown that alloantigen-activated CD4 ${ }^{+}$ $\mathrm{T}$ cells express HLA-E on their surface, resulting in an increased resistance to NK cells [90], thus suggesting a role in the regulation and differentiation of $\mathrm{CD}^{+} \mathrm{T}$ cells in vivo; those $\mathrm{T}$ cells also use HLA-E as a potential immunoregulatory therapeutic target for transplant patients. More studies are needed to evaluate the effect of polyreactive and monospecific HLA-Ib antibodies in transplantation, especially in terms of the presence of non-DSA in the sera of transplanted patients. We can hypothesize that more non-DSA reactivity of a transplant serum probably relates to the presence of polyreactive antibodies that will bind to open conformers on activated lymphocytes, suppressing their activity, and thus leading to longer graft survivalor, rather, better graft acceptance.

\section{Conclusion}

HLA antigens are the major influence on the immunological response to allografts in recipients. Matching or mismatching of HLA-Ia and -II alleles may lead to variable graft survival. The importance of HLA-Ib can be best seen in an allograft in which the donor and recipient HLA-Ia /-II types are identical. Such a case highlights the role played by HLA-Ib genes in allograft acceptance or rejection, an insight strongly reinforced by the existence of weak linkage disequilibrium between HLA-Ia and HLA-Ib alleles [59-61]. Soluble HLA-Ib and the antibodies elicited by them are critical in transplantation because of such actions as characterization of donor-specific HLA-Ia antibodies, the role played by HLA-Ib antibodies in clearing the sHLA-Ia and -Ib antigens [12].

HLA-Ib genes may be involved in the extreme variations in the survival rates of transplants. The increased expression of HLA-Ib in allograft recipients is associated with better graft acceptance, longer graft survival, and immunosuppressive-free patients. The mechanism by which HLA-Ib molecules are expressed on the surface of allografts is still unknown, but the consequences of the overexpression of these molecules-dependent as they are on the allele, available peptide, and cytokines microenvironment-are clearly beneficial for patients, protecting against early rejection by promoting graft acceptance.

Nevertheless, there are exceptions such as in cell transplantation (BMT and HSCT) and transplantation with viremia. In cell transplantation, increased expression of HLA-Ib increases the risk of developing GvHD only in patients mismatched for HLA-Ib. In transplants with viremia, the increased expression of HLA-Ib results in an increased level of viral peptide presented by HLA-E. The HLA-E/viral-peptide complex can be recognized by the TCR of CD8 ${ }^{+} \mathrm{T}$ cells or by the activating receptor CD94/ NKG2C on NK cells, both of which induce cytotoxicity in allograft cells, leading to accelerated graft loss.

HLA-Ib antibodies, generated after the immunization of HLA-Ib molecules, can be either monospecific or polyreactive. 
Monospecific antibodies can affect graft acceptance by neutralizing HLA-Ib molecules and preventing their interaction with inhibitory receptors on $\mathrm{NK}$ and $\mathrm{CD}^{+} \mathrm{T}$ cells. In contrast, polyreactive antibodies affect routine HLA antibody screening, and thus organ allocation; however, they can also inhibit the proliferation of CD4+ T cells and the memory B-cell secretion of HLA antibodies, which could promote graft acceptance.

\section{Acknowledgments}

The entire research is supported by grants from a non-profit organization, the Terasaki Family Foundation, mediated through the Terasaki Foundation Laboratory.

\section{Conflict of Interest}

None of the authors have any conflicts of interest or financial interests.

\section{References}

1. Natali PG, Bigotti A, Nicotra MR, Viora M, Manfredi D, Ferrone S. Distribution of human Class I (HLA-A,B,C) histocompatibility antigens in normal and malignant tissues of nonlymphoid origin. Cancer Res. 1984; 44(10):4679-4687.

2. Daar AS, Fuggle SV, Fabre JW, Ting A, Morris PJ. The detailed distribution of MHC Class II antigens in normal human organs. Transplantation. 1984;38(3):293-298.

3. Benacerraf B. A hypothesis to relate the specificity of T lymphocytes and the activity of I region-specific Ir genes in macrophages and B lymphocytes. J Immunol. 1978;120(6):1809-1812.

4. Unanue ER. Antigen-presenting function of the macrophage. Annu Rev Immunol. 1984;2:395-428. doi: 10.1146/annurev. iy.02.040184.002143.

5. Cresswell P. Assembly, transport, and function of MHC class II molecules. Annu Rev Immunol. 1994;12: 259-293. doi: 10.1146/ annurev.iy.12.040194.001355.

6. Petersdorf EW. The major histocompatibility complex: a model for understanding graft-versus-host disease. Blood. 2013;122(11):18631872. doi: 10.1182/blood-2013-05-355982.

7. Trowsdale J. HLA genomics in the third millennium. Curr Opin Immunol. 2005;17(5):498-504. doi: 10.1016/j.coi.2005.07.015.

8. Horton R, Wilming L, Rand V, Lovering RC, Bruford EA, Khodiyar VK, et al. Gene map of the extended human MHC. Nature Reviews Genetics. 2004;5(12):889-899. doi: 10.1038/nrg1489.

9. Robinson J, Halliwell JA, Hayhurst JH, Flicek P, Parham P, Marsh SGE The IPD and IMGT/HLA database: allele variant databases. Nucleic Acids Research. 2015. 43:D423-431.

10. Dausset J. Leucocytes, platelets and human homografts. Vox Sang. 1962;7:257-266.

11. Mayor NP, Robinson J, McWhinnie AJ, Ranade S, Eng K, Midwinter $W$, et al. HLA Typing for the Next Generation. PLoS ONE. 2015;10(5):e0127153. doi: 10.1371/journal.pone.0127153.

12. Terasaki PI. Humoral theory of transplantation. Am J Transplant. 2003;3(6):665-673.

13. Geraghty DE, Koller BH, Orr HT. A human major histocompatibility complex class I gene that encodes a protein with a shortened cytoplasmic segment. Proc Natl Acad Sci USA. 1987;84(24):9145-
9149.

14. Koller BH, Geraghty DE, Shimizu Y, DeMars R, Orr HT. HLA-E. A novel HLA class I gene expressed in resting $\mathrm{T}$ lymphocytes. J Immunol. 1988;141(3):897-904.

15. Rodgers JR, Cook RG. MHC class Ib molecules bridge innate and acquired immunity. Nat Rev Immunol. 2005;5(6):459-471. doi: $10.1038 /$ nri1635

16. Kochan G, Escors D, Breckpot K, Guerrero-Setas D. Role of nonclassical MHC class I molecules in cancer immunosuppression. Oncoimmunology. 2013;2(11):e26491. doi: 10.4161/onci.26491.

17. Sullivan LC, Hoare HL, McCluskey J, Rossjohn J, Brooks AG. A structural perspective on MHC class Ib molecules in adaptive immunity. Trends Immunol. 2006;27(9):413-20. doi: 10.1016/j.it.2006.07.006.

18. Rouas-Freiss N, Naji A, Durrbach A, Carosella E. Tolerogenic Functions of Human Leukocyte Antigen G: From Pregnancy to Organ and Cell Transplantation. Transplantation. 2007;84(1 Suppl):S21-5. doi:10.1097/01.tp.0000269117.32179.1c.

19. Lauterbach N, Wieten L, Popeijus HE, Vanderlocht J, van Zon PM, Voorter CE, et al. Peptide-induced HLA-E expression in human PBMCs is dependent on peptide sequence and the HLA-E genotype. Tissue Antigens. 2015;85(4):242-51. doi: 10.1111/tan.12525.

20.Morandi F, Pistoia V. Soluble HLA-G modulates miRNA-210 and miRNA-451 expression in activated CD4+ T lymphocytes. Int Immunol. 2013;25(5):279-285. doi: 10.1093/intimm/dxs108.

21. Le Bouteiller P, Lenfant F. Antigen-presenting function(s) of the nonclassical HLA-E, -F and -G class I molecules: the beginning of a story. Res Immunol. 1996;147(5):301-313.

22. Le Bouteiller $P$, Solier $C$. Is antigen presentation the primary function of HLA-G? Microbes Infect. 2001;3(4): 323-332.

23. Ravindranath MH, Terasaki PI, Pham T, Jucaud V. The Monospecificity of Novel Anti-HLA-E Monoclonal Antibodies Enables Reliable Immunodiagnosis, Immunomodulation of HLA-E, and Upregulation of CD8+ T Lymphocytes. Monoclon Antib Immunodiagn Immunother. 2015;34(3):135-153. doi: 10.1089/mab.2014.0096.

24. Ravindranath MH, Terasaki PI, Pham T, Jucaud V, Kawakita S. Suppression of blastogenesis and proliferation of activated CD4(+) $T$ cells: intravenous immunoglobulin (IVIg) versus novel anti-human leucocyte antigen (HLA)-E monoclonal antibodies mimicking HLA-I reactivity of IVIg. Clin Exp Immunol. 2014;178(1):154-177. doi: 10.1111/cei.12391.

25. Ravindranath MH, Kaneku H, El-Awar N, Morales-Buenrostro LE, Terasaki PI. Antibodies to HLA-E in nonalloimmunized males: pattern of HLA-Ia reactivity of anti-HLA-E-positive sera. J Immunol. 2010; 185(3):1935-1948. doi: 10.4049/jimmunol.1000424.

26. Ravindranath MH, Pham T, Ozawa M, Terasaki PI. Antibodies to HLA-E may account for the non-donor-specific anti-HLA class-Ia antibodies in renal and liver transplant recipients. Int Immunol. 2012;24(1):4357.doi: 10.1093/intimm/dxr094.

27. Ravindranath MH, Selvan SR, Terasaki PI. Augmentation of antiHLA-E antibodies with concomitant HLA-Ia reactivity in IFN $\gamma$-treated autologous melanoma cell vaccine recipients. J Immunotoxicol. 2012;9(3):282-291. doi: 10.3109/1547691X.2011.645582.

28. Moscoso J, Serrano-Vela JI, Pacheco R, Arnaiz-Villena A. HLA-G, -E and -F: allelism, function and evolution. Transpl Immunol. 2006;17(1):6164. doi: 10.1016/j.trim.2006.09.010.

29. Ishitani A, Sageshima N, Hatake K. The involvement of HLA-E and -F in 
pregnancy. Journal of Reproductive Immunology. 2006;69(2):101-13. doi: $10.1016 /$ j.jri.2005.10.004.

30. Shobu T, Sageshima N, Tokui H, Omura M, Saito K, Nagatsuka Y, et al The surface expression of HLA-F on decidual trophoblasts increases from mid to term gestation. J Reprod Immunol. 2006;72(1-2):18-32. doi: 10.1016/j.jri.2006.02.001.

31. Allan DS, Lepin EJ, Braud VM, O'Callaghan CA, McMichael AJ Tetrameric complexes of HLA-E, HLA-F, and HLA-G. J Immunol Methods. 2002;268(1):43-50.

32. Morandi F, Cangemi G, Barco S, Loredana Amoroso, Maria Giuliano, Anna Rita Gigliotti, et al. Plasma Levels of Soluble HLA-E and HLA-F at Diagnosis May Predict Overall Survival of Neuroblastoma Patients. Biomed Res Int. 2013; 956878. doi: 10.1155/2013/956878.

33. Coupel S, Moreau A, Hamidou M, Horejsi V, Soulillou JP, Charreau B. Expression and release of soluble HLA-E is an immunoregulatory feature of endothelial cell activation. Blood. 2007;109(7):2806-2814. doi: 10.1182/blood-2006-06-030213.

34. Braud VM, Allan DS, Wilson D, McMichael AJ. TAP- and tapasindependent HLA-E surface expression correlates with the binding of an MHC class I leader peptide. Curr Biol. 1998;8(1):1-10.

35. Lee N, Goodlett DR, Ishitani A, Marquardt H, Geraghty DE. HLA-E surface expression depends on binding of TAP-dependent peptides derived from certain HLA class I signal sequences. J Immunol. 1998;160(10): 4951-4960.

36. Llano M, Lee N, Navarro F, García P, Albar JP, Geraghty DE, et al. HLAE-bound peptides influence recognition by inhibitory and triggering CD94/NKG2 receptors: preferential response to an HLA-G-derived nonamer. Eur J Immunol. 1998;28(9):2854-2863. doi: 10.1002/ (SICI)1521-4141.

37. Moretta L, Romagnani C, Pietra G, Moretta A, Mingari MC. NKCTLs, a novel HLA-E-restricted T-cell subset. Trends Immunol. 2003;24(3):136-143.

38. Kraemer T, Blasczyk R, Bade-Doeding C. HLA-E: a novel player for histocompatibility. J Immunol Res. 2014; 2014: 352160. doi: $10.1155 / 2014 / 352160$.

39. Sasaki T, Ravindranath MH, Terasaki PI, Freitas MC, Kawakita S, Jucaud V. Gastric cancer progression may involve a shift in HLA-E profile from an intact heterodimer to $\beta 2$-microglobulin-free monomer. Int J Cancer. 2014;134(7):1558-15570. doi: 10.1002/ijc.28484.

40. Iwaszko M, Bogunia-Kubik K. Clinical significance of the HLA-E and CD94/NKG2 interaction. Arch Immunol Ther Exp (Warsz). 2011;59(5):353-67. doi: 10.1007/s00005-011-0137-y.

41. Pietra G, Romagnani C, Moretta L, Mingari MC. HLA-E and HLA-Ebound peptides: recognition by subsets of NK and T cells. Curr Pharm Des. 2009;15(28): 3336-3344.

42. Petrie EJ, Clements CS, Lin J, Sullivan LC, Johnson D, Huyton T, et al CD94-NKG2A recognition of human leukocyte antigen (HLA)-E bound to an HLA class I leader sequence. J Exp Med. 2008;205(3):725-735. doi: $10.1084 / \mathrm{jem} .20072525$.

43. Brooks AG, Borrego F, Posch PE, Patamawenu A, Scorzelli CJ, Ulbrecht $\mathrm{M}$, et al. Specific recognition of HLA-E, but not classical, HLA class I molecules by soluble CD94/NKG2A and NK cells. J Immunol. 1999;162(1):305-313.

44. Donadi EA, Castelli EC, Arnaiz-Villena A, Roger M, Rey D, Moreau P. Implications of the polymorphism of HLA-G on its function, regulation, evolution and disease association. Cell Mol Life Sci. 2011;68(3):369-
395. doi: $10.1007 / \mathrm{s} 00018-010-0580-7$.

45. Pistoia V, Morandi F, Wang X, Ferrone S. Soluble HLA-G: Are they clinically relevant? Semin Cancer Biol. 2007;17(6):469-479. doi: 10.1016/j.semcancer.2007.07.004.

46. Di Cristofaro J, Reynaud M, Carlini F, , Roubertoux P, Loundou A, Basire A, et al. HLA-G*01:04 UTR3 Recipient Correlates With Lower Survival and Higher Frequency of Chronic Rejection After Lung Transplantation. Am J Transplant. 2015;15(9):2413-2420. doi:10.1111/ajt.13305.

47. Pabón MA, Navarro CE, Osorio JC, , Gómez N, Moreno JP, Donado AF, et al. Impact of human leukocyte antigen molecules $\mathrm{E}, \mathrm{F}$, and $\mathrm{G}$ on the outcome of transplantation. Transplant Proc. 2014;46(9):2957-2965. doi: 10.1016/j.transproceed.2014.07.010.

48. Wainwright S, Biro P, Holmes C. HLA-F is a predominantly empty, intracellular, TAP-associated MHC class Ib protein with a restricted expression pattern. J Immunol. 2000;164(1):319-328. doi:10.4049/ jimmunol.164.1.319

49.Xu Y, Han H, Zhang F, Lv S, Li Z, Fang Z. Lesion human leukocyte antigen-F expression is associated with a poor prognosis in patients with hepatocellular carcinoma. Oncol Lett. 2015;9(1):300-304. doi: 10.3892/ol.2014.2686.

50.Gobin Sj, van Zutphen $M$, Woltman $\mathrm{AM}$, van den Elsen PJ. Transactivation of classical and nonclassical HLA class I genes through the IFN-stimulated response element. Journal of immunology. 1999;163(3):1428-1434.

51. Gobin SJ, van den Elsen PJ. Transcriptional regulation of the MHC class Ib genes HLA-E, HLA-F, and HLA-G. Hum Immunol. 2000;61(11):11021107. doi: 10.1016/S0198-8859(00)00198-1.

52. Lee N, Ishitani A, Geraghty DE. HLA-F is a surface marker on activated lymphocytes. Eur J Immunol. 2010; 40(8):2308-2318. doi: 10.1002/ eji.201040348.

53. Boyle L, Gillingham A, Munro S, Trowsdale J. Selective export of HLA-F by its cytoplasmic tail. J Immunol. 2006;176(11):6464-6472.

54. Lepin EJ, Bastin JM, Allan DS, Roncador G, Braud VM, Mason DY, et al. Functional characterization of HLA-F and binding of HLA-F tetramers to ILT2 and ILT4 receptors. Eur J Immunol. 2000;30(12):3552-61. doi: 10.1002/1521-4141.

55. Goodridge JP, Burian A, Lee N, Geraghty DE. HLA-F and MHC class I open conformers are ligands for NK cell Ig-like receptors. J Immunol. 2013;191(7):3553-62.doi: 10.4049/jimmunol.1300081.

56. Goodridge JP, Lee N, Burian A, Tykodi SS, Warren EH, Yee C, et al. HLA-F and MHC-I open conformers cooperate in a MHC-I antigen cross-presentation pathway. J Immunol. 2013;191(4):1567-1577. doi: 10.4049/jimmunol.1300080.

57. Goodridge JP, Burian A, Lee N, Geraghty DE. HLA-F complex without peptide binds to MHC class I protein in the open conformer form. J Immunol. 2010; 184(11): 6199-6208. doi: 10.4049/ jimmunol.1000078.

58. Rouas-Freiss N, LeMaoult J, Moreau P, Dausset J, Carosella ED. HLA-G in transplantation: a relevant molecule for inhibition of graft rejection? Am J Transplant. 2003;3(1):11-16.

59. Tamouza R, Rocha V, Busson M, Fortier C, El Sherbini SM, Esperou $\mathrm{H}$, et al. Association of HLA-E polymorphism with severe bacterial infection and early transplant-related mortality in matched unrelated bone marrow transplantation. Transplantation. 2005;80(1):140-144.

60.Zhu Z-LL, Wu X-JJ, Wu D-PP, Feng YF, Xu Y, Ma X, Han Y, Liu YJ, Li 
CX, et al.Influence of HLA-E polymorphism on cytomegalovirus infection after HLA-matched hematopoietic stem cell transplantation. Zhongguo Shi Yan Xue Ye Xue Za Zhi. 2013;21(4):990-994. doi: 10.7534/j.issn.1009-2137.2013.04.034.

61. Romero V, Larsen CE, Duke-Cohan JS, Fox EA, Romero T, Clavijo OP, et al. Genetic fixity in the human major histocompatibility complex and block size diversity in the class I region including HLA-E. BMC Genet. 2007; 12(8):14. doi: 10.1186/1471-2156-8-14.

62. Rebmann V, da Silva Nardi F, Wagner B, Horn PA. HLA-G as a tolerogenic molecule in transplantation and pregnancy. J Immunol Res. 2014;2014:297073. doi: 10.1155/2014/297073.

63. Felício LP, Porto IO, Mendes-Junior CT, Veiga-Castelli LC, Santos KE, Vianello-Brondani RP, et al. Worldwide HLA-E nucleotide and haplotype variability reveals a conserved gene for coding and $3^{\prime}$ untranslated regions. Tissue Antigens. 2014;83(2):82-93. doi:10.1111/tan.12283.

64. Carosella ED, Favier B, Rouas-Freiss N, Moreau P, Lemaoult J. Beyond the increasing complexity of the immunomodulatory HLA-G molecule. Blood. 2008;111(10): 4862-4870. doi: 10.1182/ blood-2007-12-127662.

65. Nguyen S, Dhedin N, Vernant J-PP, Kuentz M, Al Jijakli A, Rouas-Freiss $\mathrm{N}$ et al. NK-cell reconstitution after haploidentical hematopoietic stemcell transplantations: immaturity of NK cells and inhibitory effect of NKG2A override GvL effect. Blood. 2005; 105(10):4135-4142. doi: 10.1182/blood-2004-10-4113.

66. Hosseini E, Schwarer AP, Ghasemzadeh M. The impact of HLA-E polymorphisms in graft-versus-host disease following HLA-E matched allogeneic hematopoietic stem cell transplantation. Iran J Allergy Asthma Immunol. 2012;11(1):15-21.

67. Tamouza R, Busson M, Rocha V, Fortier C, Haddad Y, Brun M, et al. Homozygous statusfor HLA-E*0103 confers protection from acute graft-versus-host disease and transplant-related mortality in HLA-matched sibling hematopoietic stem cell transplantation. Transplantation. 2006;82(11):1436-1440.doi: 10.1097/01. tp.0000244598.92049.dd.

68. Hunt JS. Stranger in a strange land. Immunol Rev. 2006;213(1)36-47. doi: 10.1111/j.1600-065X.2006.00436.x.

69. Rebmann V, van der Ven K, Pässler M, Pfeiffer K, Krebs D, GrosseWilde H. Association of soluble HLA-G plasma levels with HLA-G alleles. Tissue Antigens. 2001; 57(1):15-21.

70. Hviid TV, Rizzo R, Christiansen OB, melchiorri L, Lindhard A, Baricordi OR. HLA-G and IL-10 in serum in relation to HLA-G genotype and polymorphisms. Immunogenetics. 2004;56(3):135-41. doi: 10.1007/ s00251-004-0673-2.

71. La Nasa G, Littera R, Locatelli F, Lai S, Alba F, Caocci G, et al. The human leucocyte antigen-G 14-basepair polymorphism correlates with graftversus-host disease in unrelated bone marrow transplantation for thalassaemia. Br J Haematol. 2007;139(2):284-8. doi: 10.1111/j.13652141.2007.06779.x.

72. Rousseau P, Discorde M Le, Mouillot G, Marcou C, Carosella ED, Moreau $P$. The 14 bp deletion-insertion polymorphism in the $3^{\prime}$ UT region of the HLA-G gene influences HLA-G mRNA stability. Hum Immunol. 2003;64(11):1005-1010.

73. Deschaseaux F, Delgado D, Pistoia V, Giuliani M, Morandi F, Durrbach A. HLA-G in organ transplantation: towards clinical applications. Cell Mol Life Sci. 2010;68(3):397-404. doi: 10.1007/s00018-010-0581-6.

74. Dharnidharka VR, Caillard S, Agodoa LY, Abbott KC. Infection frequency and profile in different age groups of kidney transplant recipients. Transplantation. 2006;81(12):1662-1667. doi: 10.1097/01. tp.0000226068.66819.37.

75. Ramanan P, Razonable RR. Cytomegalovirus infections in solid organ transplantation: a review. Infect Chemother. 2013;45(3):260-271. doi: 10.3947/ic.2013.45.3.260.

76. Egli A, Binggeli S, Bodaghi S, Dumoulin A, Funk GA, Khanna N, et al. Cytomegalovirus and polyomavirus BK posttransplant. Nephrol Dial Transplant. 2007;22(8):viii72-viii82. doi: 10.1093/ndt/gfm648.

77. Allard M, Tonnerre P, Nedellec S, Oger R, Morice A, Guilloux Y, et al. HLA-E-restricted cross-recognition of allogeneic endothelial cells by CMV-associated CD8 T cells: a potential risk factor following transplantation. PLoS ONE. 2012;7(11):e50951. doi: 10.1371/journal. pone.0050951.

78. Katznelson S, Wang XM, Chia D, Chia D, Ozawa M, Zhong HP, et al. The inhibitory effects of pravastatin on natural killer cell activity in vivo and on cytotoxic T lymphocyte activity in vitro. J Heart Lung Transplant. 1998;17(4):335-340.

79. Sheshgiri R, Rao V, Tumiati LC, Xiao R, Prodger JL, Badiwala M, et al. Progesterone induces human leukocyte antigen-g expression in vascular endothelial and smooth muscle cells. Circulation. 2008;118(14):S58-64. doi: 10.1161/CIRCULATIONAHA.107.757781.

80. Genbacev O, Zhou Y, Ludlow JW, Fisher SJ. Regulation of human placental development by oxygen tension. Science. 1997;277(5332): 1669-1672.

81. Mouillot G, Marcou C, Zidi I, Guillard C, Sangrouber D, Carosella ED, Moreau P, et al. Hypoxia modulates HLA-G gene expression in tumor cells. Hum Immunol. 2007;68(4):277-85. doi: 10.1016/j. humimm.2006.10.016.

82. Kumar G, Date OS, Kim KS, Manjunath R. Infection of human amniotic and endothelial cells by Japanese encephalitis virus: Increased expression of HLA-F. Virology. 2014;471-473:29-37. doi: 10.1016/j. virol.2014.09.022.

83. Suárez-Alvarez B, Rodriguez RMM, Calvanese V, Miguel ABG, Blanco G, Steve TS, et al. Epigenetic mechanisms regulate MHC and antigen processing molecules in human embryonic and induced pluripotent stem cells. PLoS ONE. 2010;5(4): e10192. doi: 10.1371/journal. pone. 0010192 .

84. Stewart L, Evans N, Bexon KJ, van der Meer DJ, Williams GA. Differentiating between monozygotic twins through DNA methylation-specific high-resolution melt curve analysis. Anal Biochem. 2015;476:36-39. doi: 10.1016/j.ab.2015.02.001.

85. Sizzano F, Testi M, Zito L, , Crocchiolo R, Troiano M, Mazzi B, et al. Genotypes and haplotypes in the 3' untranslated region of the HLA-G gene and their association with clinical outcome of hematopoietic stem cell transplantation for beta-thalassemia. Tissue Antigens. 2012;79(5):326-32. doi: 10.1111/j.1399-0039.2012.01862.x.

86. Torres MI, Luque J, Lorite P, Isla-Tejera B, Palomeque T, Aumente $M D$, et al. 14-Base pair polymorphism of human leukocyte antigen-G as genetic determinant in heart transplantation and cyclosporine therapy monitoring. Hum Immunol. 2009;70(10):830-5. doi: 10.1016/j.humimm.2009.07.012.

87. Castellaneta A, Mazariegos G, Nayyar N, Zeevi A, Thomson AW. HLA-G Level on Monocytoid Dendritic Cells Correlates With Regulatory T-Cell Foxp3 Expression in liver transplant tolerance. Transplantation. 2011; 91(10):1132-1140. doi: 10.1097/TP.0b013e31821414c9.

88. Chen H-F, Yu C-Y, Chen M-J, Chou SH, Chiang MS, Chou WH, et al. 
Characteristic expression of major histocompatibility complex and immune privilege genes in human pluripotent stem cells and their derivatives. Cell Transplant. 2015;24(5):845-864. doi: $10.3727 / 096368913 \times 674639$.

89. Brugière 0 , Thabut 0 , Pretolani $M$, Krawice-Radanne I, Dill C, Herbreteau A, et al. Immunohistochemical Study of HLA-G Expression in Lung Transplant Recipients. Am J Transplant. 2009;9(6):1427-1438. doi:10.1111/j.1600-6143.2009.02650.x.

90. Takao S, Ishikawa T, Yamashita K, Uchiyama T. The rapid induction of HLA-E is essential for the survival of antigen-activated naive CD4 T cells from attack by NK cells. J Immunol. 2010;185(10):6031-40. doi: 10.4049/jimmunol.1000176.

91. Bresciani A, Pirozzi G, Spera M, Lombardi ML, Ambrosone L, Migliares $S$, et al. Increased level of serum HLA class I antigens in patients with systemic lupus erythematosus. Correlation with disease activity. Tissue Antigens. 1998;52(1):44-50. doi: 10.1111/j.1399-0039.1998. tb03022.x.

92. Adamashvili I, Wolf R, Aultman D, Milford EL, Jaffe S, Hall V, et al. Soluble HLA-I (s-HLA-I) synthesis in systemic lupus erythematosus. Rheumatol Int. 2003;23(6):294-300. doi: 10.1007/s00296-003-03063.

93. Puppo F, Contini P, Ghio M, Indiveri F. Soluble HLA class I molecules/ CD8 ligation trigger apoptosis of CD8+ cells by Fas/Fas-ligand interaction. ScientificWorldJournal. 2002;12(2):421-3. doi: 10.1100/ tsw.2002.122.

94. Puppo F, Scudeletti M, Indiveri F, Ferrone S. Serum HLA class I antigens: markers and modulators of an immune response? Immunol Today. 1995;16(3):124-7.

95. Luque J, Torres MI, Aumente MD, Marín J, García-Jurado G, González $\mathrm{R}$, et al. Soluble HLA-G in heart transplantation: their relationship to rejection episodes and immunosuppressive therapy. Hum Immunol. 2006;67(4-5):257-63. doi: 10.1016/j.humimm.2006.02.034.

96. Créput C, Durrbach A, Menier C, Guettier C, Samuel D, Dausset J, et al. Human leukocyte antigen-G (HLA-G) expression in biliary epithelial cells is associated with allograft acceptance in liver-kidney transplantation. J Hepatol. 2003 ;39(4):587-94.

97. Xiao L, Zhou WQ, Shi BY, Feng K, He XY, Wei YX, et al. HLA-G expression in the peripheral blood of live kidney transplant recipients. Chin Med J. 2013;126(14):2652-5.

98. Qiu J, Terasaki PI, Miller J, Mizutani K, Cai J, Carosella ED. Soluble HLA-G expression and renal graft acceptance. Am J Transplant. 2006;6(9):2152-6. doi: 10.1111/j.1600-6143.2006.01417.x.

99. Boyson J, Erskine R, Whitman M, Chiu M, Lau JM, Koopman LA ,et al. Disulfide bond-mediated dimerization of HLA-G on the cell surface. Proc Natl Acad Sci U S A. 2002;99(25):16180-5. doi:10.1073/ pnas. 212643199.

100. Ezeakile M, Portik-Dobos V, Wu J, Horuzsko DD, Kapoor R, Jagadeesan M, et al. HLA-G dimers in the prolongation of kidney allograft survival. J Immunol Res. 2014;2014:153981. doi: 10.1155/2014/153981.
101. Rhynes VK, McDonald JC, Gelder FB, et al. Soluble HLA class I in the serum of transplant recipients. Ann Surg. 1993;217(5):485-9; discussion 489-91.

102. Reed EF, Hong B, Ho E, Harris PE, Weinberger J, Suciu-Foca N. Monitoring of soluble HLA alloantigens and anti-HLA antibodies identifies heart allograft recipients at risk of transplant-associated coronary artery disease. Transplantation. 1996;61(4):566-72.

103. Zavazava N, Böttcher H, Ruchholtz WM. Soluble MHC class I antigens (sHLA) and anti-HLA antibodies in heart and kidney allograft recipients. Tissue Antigens. 1993;42(1):20-6.

104. Ravindranath MH, Taniguchi M, Chen CW, Ozawa M, Kaneku H El-Awar N, et al. HLA-E monoclonal antibodies recognize shared peptide sequences on classical HLA class Ia: relevance to human natural HLA antibodies. Mol Immunol. 2010;47(5):1121-31. doi: 10.1016/j.molimm.2009.10.024.

105. Ravindranath MH, Pham T, El-Awar N, Kaneku H, Terasaki PI. AntiHLA-E mAb 3D12 mimics MEM-E/02 in binding to HLA-B and HLA-C alleles: Web-tools validate the immunogenic epitopes of HLA-E recognized by the antibodies. Mol Immunol. 2011;48(4):423-30. doi: 10.1016/j.molimm.2010.09.011.

106. Ravindranath MH, Zhu D, Pham T, Jucaud V, Hopfield J, Kawakita S, et al. Anti-HLA-E monoclonal antibodies reacting with HLA-la and lb alleles like IVIg as potential IVIg-immunomimetics: an evolving therapeutic concept. Clin Transpl. 2013:293-305.

107. Zhu D, Ravindranath MH, Terasaki PI, Miyazaki T, Pham T, Jucaud V. Suppression of allo-human leucocyte antigen (HLA) antibodies secreted by B memory cells in vitro: intravenous immunoglobulin (IVIg) versus a monoclonal anti-HLA-E IgG that mimics HLA-I reactivities of IVIg. Clin Exp Immunol. 2014;177(2):464-77. doi: 10.1111/cei.12307.

108. Ravindranath MH, Terasaki PI, Pham T, Jucaud V, Kawakita S. Therapeutic preparations of IVIg contain naturally occurring anti-HLA-E antibodies that react with HLA-Ia (HLA-A/-B/Cw) alleles. Blood. 2013; 121(11):2013-28. doi: 10.1182/ blood-2012-08-447771.

109. Morales-Buenrostro LE, Terasaki PI, Marino-Vázquez LA, Lee JH, El-Awar N, Alberú J. "Natural" human leukocyte antigen antibodies found in nonalloimmunized healthy males. Transplantation. 2008;86(8): 1111-5. doi: 10.1097/TP.0b013e318186d87b.

110. Visentin J, Guidicelli G, Bachelet T, Jacquelinet C, Audry B, Nong $\mathrm{T}$, et al. Denatured class I human leukocyte antigen antibodies in sensitized kidney recipients: prevalence, relevance, and impact on organ allocation. Transplantation. 2014;98(7):738-44. doi: 10.1097/TP.0000000000000229.

111. Demaria S, Schwab R, Bushkin Y. The origin and fate of beta $2 \mathrm{~m}$-free MHC class I molecules induced on activated T cells. Cell Immunol. 1992;142(1):103-13. 